\title{
Korelasi Marshall CT Score sebagai Prediktor Mortalitas pada Penderita Cedera Kepala di RSUD dr Abdul Aziz Singkawang Titah A C Kumoro ${ }^{1}$, Sonny G R Saragih ${ }^{2}$, Diana Natalia ${ }^{3}$
}

\author{
${ }^{1}$ Program Studi Kedokteran, FK UNTAN \\ ${ }^{2}$ SMF Ilmu Bedah Saraf, RSUD dr Abdul Aziz Singkawang \\ ${ }^{3}$ Departemen Parasitologi Medik, Program Studi Kedokteran, FK UNTAN
}

\begin{abstract}
Abstrak
Latar Belakang. Cedera kepala termasuk masalah global dan salah satu penyebab terbanyak kematian dan kecacatan diseluruh dunia. Insiden cedera kepala banyak terjadi pada usia produktif, yaitu pada usia 15-24 tahun. Di Indonesia kasus trauma merupakan penyebab kematian terbanyak ke-4 setelah stroke, tuberkulosis dan hipertensi. Insiden terjadinya cedera kepala di Indonesia relatif tinggi, terutama cedera kepala akibat kecelakaan lalu lintas yang mencapai angka 19,6\%. Di Kalimantan Barat sendiri jumlah korban meninggal akibat kecelakaan lalu lintas terjadi sebanyak 560 orang pada tahun 2013, 550 orang pada tahun 2014 dan 470 orang pada tahun 2015. Sedangkan insiden kecelakaan lalu lintas di Kota Singkawang tercatat 211 kasus pada tahun 2012, 168 kasus pada tahun 2013, 120 kasus pada tahun 2014, 110 kasus pada tahun 2015 dan terdapat 71 kasus pada tahun 2016. Metode. Penelitian ini bersifat analitik dengan menggunakan pendekatan potong lintang. Dilakukan di RSUD Dr Abdul Aziz Kota Singkawang. Penelitian ini menggunakan total sampling dari seluruh rekam medis pasien bedah saraf dengan cedera kepala sedang dan berat di RSUD Abdul Aziz Kota Singkawang. Data yang diambil adalah hasil penilaian CT Scan pasien menggunakan Marshall CT Score dan penilaian hasil keluar, yang diambil berdasarkan rekam medis pasien. Sampel minimal yang diambil sebanyak 30 sampel yang sesuai dengan kriteria inklusi dan eksklusi. Hasil. terdapat korelasi positif yang sangat kuat antara Marshall CT Score dan mortalitas pada pasien cedera kepala sedang dan berat dengan nilai r mencapai 0.943 dari 66 data. Kesimpulan. Terdapat korelasi positif yang sangat kuat antara Marshall CT Score dan mortalitas, yang mana semakin tinggi nilai Marshall maka semakin tinggi angka mortalitas. Nilai GCS yang terbanyak pada subjek penelitian adalah 12. Nilai Marshall CT Score terbanyak yaitu kategori diffuse injury II, dan persentase mortalitas tertinggi pada kategori non evacuated mass lesion. Angka mortalitas pada pasien cedera kepala sedang dan berat adalah 26 orang.
\end{abstract}

Kata Kunci : Cedera Kepala, Marshall CT Score, Mortalitas

Background. Head injury is a global issue and one of the leading cause of death and disability worldwide. Individuals suffering from head injuries usually experience cognitive impairment, physical disorder and emotional problem. The incidence of head injuries occurs in many productive ages, ie, at the age of 15-24 years. In Indonesia death caused by trauma is the fourth most common case of death after stroke, tuberculosis and hypertension. The incidence of head injury in Indonesia is relatively high, especially due to traffic accidents that reached $19.6 \%$ cases. In West Kalimantan the number of deaths from traffic accident occurred as many as 560 people in 2013, 550 people in 2014 and 470 people in 2015. While recorded in Singkawang city there are 211 cases in 2012, 168 cases in 2013, 120 cases in 2014, 110 cases in 2015 and 71 cases in 2016. Method. This research was an analytic study using cross sectional approach. Conducted in Dr Abdul Aziz general hospital. This study used total sampling from all medical records of neurosurgeon patients with moderate and severe head injury in Dr Abdul Aziz general hospital. The data taken are the results of CT Scan assessment of patients using Marshall CT Score and outcome assessment, taken based on the patient's medical records. Minimum samples taken as many as 30 samples according to inclusion and exclusion criteria. Result. there was a very strong positive correlation between Marshall CT Score and mortality in patients with moderate and severe head injury with $r$ value 0.943 out of 66 data.. Conclusion. There was a very strong correlation between Marshall CT score and mortality, which is higher the Marshall score means higher the mortality rate. The most GCS score of subject 12. The most Marshall's score in subject is diffuse injury II, and the highest mortality rate is non evacuated mass lession (VI). The number of martality in patients with moderate and severe head injury are 26 people.

Keywords: Head injury, Marshall CT Score, Mortality 
PENDAHULUAN

Cedera kepala termasuk masalah global dan salah satu penyebab terbanyak kematian dan kecacatan diseluruh dunia. ${ }^{1,2}$ Cedera kepala juga merupakan penyebab kematian ketiga dari semua jenis trauma yang dikaitkan dengan kematian. ${ }^{3}$ Pasien yang selamat dari cedera kepala sering kali menghadapi tantangan seumur hidup dan penurunan kualitas hidup. Individu yang menderita cedera kepala biasanya mengalami penurunan kognitif, gangguan fisik, dan masalah emosional. $^{2}$ Sebagian besar cedera kepala terjadi akibat kecelakaan lalu lintas. $^{4}$

Insiden cedera kepala banyak terjadi pada usia produktif, yaitu pada usia 1524 tahun. Insiden terjadinya cedera kepala di Amerika tahun 2013 pada usia 15-24 tahun dilaporkan sebanyak 917,5/100 000 dan insiden tersebut terus meningkat dengan meningkatnya penggunaan kendaraan bermotor. ${ }^{5-7} \mathrm{Di}$

Indonesia kasus trauma merupakan penyebab kematian terbanyak ke-4 setelah stroke, tuberkulosis dan hipertensi. Insiden terjadinya cedera kepala di Indonesia relatif tinggi, terutama cedera kepala akibat kecelakaan lalu lintas yang mencapai angka $19,6 \% .8,9$

Korban meninggal akibat kecelakaan lalu lintas di Kalimantan Barat terjadi sebanyak 560 orang pada tahun 2013, 550 orang pada tahun 2014 dan 470 orang pada tahun $2015^{10}$ sedangkan di kota Pontianak kecelakaan lalu lintas banyak terjadi pada mahasiswa dan pelajar. Tercatat ada 94 orang pada tahun 2014 dan 63 orang pada tahun 2015 korban meninggal akibat kecelakaan lalu lintas. 11

Insiden kecelakaan lalu lintas di Kota Singkawang tercatat 211 kasus pada tahun 2012, 168 kasus pada tahun 2013, 120 kasus pada tahun 2014, 110 kasus pada tahun 2015 dan terdapat 71 
kasus pada tahun 2016. ${ }^{12}$ Data RSUD

DR Abdul Aziz Kota Singkawang terdapat 529 kasus cedera kepala pada periode Januari 2016 - Mei 2017.

\section{Glasgow Coma Scale (GCS)} merupakan salah satu metode klinis yang paling banyak digunakan untuk memprediksikan suatu akibat dari cedera kepala. ${ }^{12}$

Penilaian Glasgow Coma Scale didasari dengan memberikan stimulus terhadap pasien dan melihat bagaimana respon membuka mata, respon verbal dan respon motorik pasien tersebut. ${ }^{13}$ Glasgow Coma Scale adalah suatu sistem penilaian yang telah distandarisasi untuk menilai status neurologis pasien dengan trauma kapitis. Nilai GCS yang akurat hanya bisa didapat setelah resusitasi tetapi sebelum diberikan sedasi.

Nilai GCS yang akurat ini digunakan untuk pengobatan langsung dan untuk prediksi hasil pada pasien. ${ }^{14}$ Pada pasien yang mengalami cedera kepala berat, nilai GCS akurat tidak bisa didapat, oleh karena itu metode ampuh yang dapat dilakukan adalah melalui gambaran radiologi. CT scan masih merupakan pilihan metode gambaran radiologi yang ideal untuk menilai cedera kepala yang diikuti kerusakan struktur akut. ${ }^{1}$

$$
\text { Computed Tomography }
$$

dirasakan sangat bermanfaat untuk prognosis. Pencitraan seperti kompresi sisterna basal, trauma perdarahan subaraknoid, midline shift, atau munculnya ketidak normalan telah terbukti $>70 \%$ terkait dengan prediksi trauma kepala kelas I dan II. ${ }^{15} \mathrm{CT}$ mempermudah kita untuk meningkatkan pengetahuan mengenai hasil dari pasien dengan trauma kepala. ${ }^{1,16}$ Untuk memprediksi hasil dari pasien trauma kepala, terdapat dua sistem penilaian, yaitu Marshall CT score dan Rotterdam score. ${ }^{17,18}$

Marshall CT score, dikembangkan pada tahun 1991 oleh Marshal, merupakan klasifikasi CT yang paling 
banyak digunakan pada pasien cedera kepala. Terdapat tiga variabel utama pada Marshall CT score yaitu : terdapatnya massa pada cedera, status dari perimesencephalic cistern, dan derajat midline shift. Biasanya Marshall CT score tidak digunakan pada prognosis namun lebih sebagai alat pendeskripsi. Akan tetapi, kemampuan prediksi dari Marshall CT score beragam pada tiap penelitian. walaupun Marshall CT score sangat populer digunakan, sistem ini memiliki keterbatasan. $15,18-21$

Menurut uraian diatas, peneliti tertarik untuk mencari tahu apakah terdapat korelasi antara Marshall CT score sebagai prediktor mortalitas pada penderita cedera kepala sedang dan berat di Rumah Sakit Umum Daerah Abdul Aziz Kota Singkawang. dengan menggunakan pendekatan potong lintang. Penelitian ini dilakukan di RSUD Dr Abdul Aziz Kota Singkawang. Waktu penelitian dari bulan April 2017 sampai bulan November 2017. Populasi penelitian adalah pasien cedera kepala di RSUD Dr. Abdul Aziz kota Singkawang. Sampel yang diteliti pada penelitian ini adalah semua populasi yang memenuhi kriteria inklusi. Penelitian ini menggunakan total sampling dari seluruh rekam medis pasien bedah saraf dengan cedera kepala sedang dan berat di RSUD Abdul Aziz Kota Singkawang. Data dari penelitian ini dikumpulkan melalui rekam medis dan gambaran CT-Scan pasien, kemudian dilakukan analisis univariat dan analisis bivariat. Analisis bivariat yang dilakukan dalam penelitian ini adalah uji spearman's rho.

\section{HASIL}

RSUD DR Abdul Aziz Kota
Penelitian ini bersifat analitik

\section{METODE}

Singkawang merupakan sebuah rumah 
sakit yang menjadi tempat rujukan terhadap pasien cedera kepala dari berbagai daerah di Kalimantan Barat. Terdapat satu orang dokter spesialis bedah saraf yang memiliki kompetensi dalam menangani kasus cedera kepala secara medis di rumah sakit tersebut.

Data di RSUD DR Abdul Aziz Kota Singkawang periode Januari 2016 - Mei 2017 terdapat 529 kasus pasien cedera kepala, dengan jumlah pasien laki-laki sebesar $60,3 \%$ dan perempuan 39,7\%. Dari data tersebut didapatkan pasien cedera kepala yang hidup sebesar $89,8 \%$ dan meninggal $10,2 \%$. Kejadian cedera kepala ringan $72,8 \%$, pasien cedera kepala sedang hingga berat sebesar $27,2 \%$.

\section{RSUD DR Abdul Aziz Kota} Singkawang mulai memiliki fasilitas CT-Scan sejak tahun 2016, sehingga pasien cedera kepala pada tahun sebelumnya, khususnya periode 20142015, akan dirujuk ke RS Santo Vincentius Kota Singkawang untuk dilakukan CT-Scan.

Penelitian ini melibatkan 66 sampel penelitian. Sebagian besar sampel dieksklusikan karena tidak menjalani atau terdapat data $C T$ Scan dan data rekam medis yang tidak lengkap. Hasil penelitian ini menunjukkan data umum karakteristik subjek penelitian meliputi usia, jenis kelamin, nilai GCS dan status keluar. Hasil penelitian juga menunjukkan karakteristik parameter penilaian Marshall CT Score subjek penelitian yang diuraikan sebagai berikut.

a. Karakteristik Subjek Penelitian

Usia rata-rata subjek penilitian adalah $36,27 \pm 19.01$ tahun. Usia termuda subjek penelitian adalah 1 tahun dan yang paling tua adalah 77 tahun. Persentase rentang usia terbesar subjek penelitian pada umur $36-$ 47 tahun yaitu $30,30 \%$ dan persentase terkecil pada rentang umur $60-71$ tahun sebesar 
$3,03 \%$. Sebagian besar subjek

penelitian berjenis kelamin laki-

laki, yaitu sebanyak 47 orang dengan persentase $71,21 \%$.

Penelitian ini hanya mengumpulkan data GCS pada pasien cedera kepala sedang dan berat. Rata-rata nilai GCS pada sampel adalah 9,67 \pm 2.80 , dengan cedera kepala sedang (GCS 9 - 12) merupakan cedera yang paling banyak terjadi, dengan persentase sebesar $70 \%$ dan $30 \%$ sisanya merupakan cedera kepala berat. Nilai GCS tertinggi dan terbanyak yaitu 12 , nilai terendah 3 dan yang paling sedikit yaitu 4 dan 5 .

Pada pasien dengan GCS 9 menandakan tingkat kesadaran somnolen, sedangkan nilai GCS 3 menandakan tingkat kesadaran koma. Dari total subjek, penelitian angka kematian mencapai $42.42 \%$ dan sisanya memiliki hasil keluaran yang baik.

b. Karakteristik parameter penilaian Marshall CT Score

Berdasarkan sistem skoring Marshall subjek penelitian, didapatkan bahwa kategori nonevacuated mass lession memiliki tingkat mortalitas yang paling tinggi mencapai $100 \%$. Kategori diffuse injury I memiliki tingkat mortalitas yang paling sedikit hanya $16,67 \%$, yang mana angka tersebut dapat menjadi lebih kecil apabila cedera kepala ringan juga dimasukkan kedalam kriteria inklusi.

Pada subjek penelitian didapatkan diffuse injury II merupakan skor yang paling banyak didapatkan.

Pada penelitian ini korelasi Marshall CT score sebagai prediktor mortalitas pada penderita cedera kepala sedang dan 
berat dianalisis menggunakan program

Statistical Product and Service Solution

(SPSS) 23. Sebelum memasukkan data

ke dalam program SPSS, angka mortalitas yang didapatkan diubah menjadi proporsi mortalitas agar data dari setiap kategori memiliki derajat yang sama. Setelah dilakukan uji linearitas dan dilanjutkan dengan perhitungan menggunakan korelasi spearman's rho, didapatkan $\mathrm{r}=0.943$ dengan derajat error 0,005. hal ini menandakan bahwa terdapat korelasi positif yang sangat kuat (r mendekati 1) antara Marshall CT Score dan mortalitas pada pasien cedera kepala sedang dan berat. Dimana semakin tinggi nilai Marshall maka semakin tinggi pula mortalitasnya.

\section{PEMBAHASAN}

Angka kasus cedera kepala di RSUD DR Abdul Aziz Kota Singkawang periode Januari 2016 - Mei 2017 terhitung sebanyak 529 kasus dengan etiologi yang bermacam-macam, seperti kecelakaan lalu lintas, jatuh, tertembak, dll. Subjek penlitian yang digunakan berdasarkan kriteria inklusi penelitian berjumlah 66 dari 529 kasus tersebut.

Cedera kepala disebabkan oleh benturan pada bagian kepala secara langsung ataupun tidak langsung yang dapat terjadi dengan mekanisme benturan secara mendadak ataupun terus-menerus oleh gaya akselerasi, deselerasi dan serta rotasi.

Cedera kepala dapat berakibat fatal, dapat menyebabkan disabilitas hingga mortalitas. ${ }^{6,38,39}$ Cedera kepala dapat memberikan efek secara fisik, fisiologis, kognitif, emosi dan sosial, dan dapat mengakibatkan cedera pada otak dan perdarahan intrakranial yang meliputi perdarahan epidural, subdural, subarakhnoid, intraserebral serta intraventrikular. $6,38,39$

Perdarahan intrakranial dapat mengganggu keadaan hemodinamik 
sehingga dapat menyebabkan iskemi hingga infark pada jaringan otak serta dapat menimbulkan lesi desak ruang yang dapat merusak jaringan otak dan mengganggu fungsi otak. Cedera otak akibat perdarahan intrakranial tersebut dapat menyebabkan kerusakan jaringan kortikal dan subkortikal otak yang mengakibatkan terganggunya mekanisme sistem saraf otonom yang merupakan fungsi fisiologis penting seperti dalam pengaturan pernapasan, tekanan darah hingga sistem kompleks kesadaran. 40,41

Indikasi untuk dilakukan operasi evakuasi pada perdarahan epidural dan intraserebral jika volume perdarahan $\geq$ $30 \mathrm{ml}$, sedangkan pada perdarahan subdural apabila terdapat perdarahan $\geq$ 10mm. dilakukannya operasi evakuasi perdarahan karena hal tersebut dapat meningkatkan tekanan intrakranial secara signifikan dan dapat berakibat fatal seperti herniasi hingga terjadinya kematian. ${ }^{24,40}$ Sedangkan menurut kategori evacuated mass lesion (V),Marshall CT Score, dilakukan indikasi operasi evakuasi apabila pada hasil CT-Scan didapatkan sisterna basalis terhimpit atau tidak terlihat, terjadi pergeseran garis tengah (Midline Shift) $>5 \mathrm{~mm}$, dan atau terdapat lesi densitas tinggi atau campuran $>25$ ml. ${ }^{17}$

Pada penelitian ini, kasus cedera kepala yang paling banyak terjadi pada jenis kelamin laki-laki, dengan kelompok usia terbanyak $36-47$ tahun. Berdasarkan epidemiologi cedera kepala dari Centers for Disease Control and Prevention, kecelakaan lalu lintas dan terjatuh merupakan penyebab terbanyak. 6

Berdasarkan penelitian Langlois $\mathrm{dkk}^{42}$ di Amerika Serikat, jenis kelamin laki-laki memiliki resiko cedera kepala dua kali lebih besar diabndingkan wanita dan banyak pada usia produktif $15-24$ tahun, karena pada usia produktif lebih banyak mengendarai kendaraan 
sehingga lebih beresiko terhadap kecelakaan lalu lintas. 6,42

Penelitian ini hanya menggunakan sampel cedera kepala sedang dan berat, yang mana memiliki prognosis atau hasil outcome yang lebih buruk. ${ }^{42}$ Cedera kepala sedang merupakan derajat cedera kepala terbanyak pada penelitian ini, mencapai $70 \%$ dengan rerata GCS 9,67 $\pm \quad 2,8, \quad$ sedangkan $30 \%$ lainnya merupakan cedera kepala berat.

\section{Penilaian Marshall CT Score} merupakan salah satu sistem penilaian cedera kepala yang paling sering digunakan. Sistem skoring ini terdiri atas 6 kategori penilaian, yaitu diffuse injury I, diffuse injury II, diffuse injury III, diffuse injury IV, evacuated mass lesion (V), dan non-evacuted mass lesion (VI). Berdasarkan penelitian Mbemba $^{34}, \quad$ Marshall $C T$ Score memiliki hubungan yang erat terhadap kematian dini.

Hal ini dikarenakan dalam sistem skoring Marshall terdapat penilaian terhadap terlihat atau tidaknya sisterna basal, terdapatnya midline shift, dan juga massa perdarahan dalam $C T$ Scan pasien. Pada penelitan ini jumlah data pasien diffuse injury I sulit didapatkan, dikarenakan sebagian besar pasien cedera kepala sedang dan berat memiliki gambaran CT Scan kepala yang lebih buruk.

Menurut metaanalysis yang dilakukan oleh peneliti IMPACT, memberikan bukti kuat dalam mendukung faktor-faktor penentu dalam kasus cedera kepala. Faktor- faktor tersebut diantaranya adalah nilai GCS, usia, reaksi pupil, pasien dengan hipotensi dan gambaran CT Scan.

Nilai GCS awal yang diperiksa setelah resusitasi hemodinamik terbukti sebagai faktor penentu hasil akhir pada kasus cedera kepala berat, yang mana skor terburuk adalah skor yang paling rendah (3). Usia merupakan salah satu faktor yang paling berpengaruh terhadap hasil akhir kasus cedera kepala. Belum 
dapat dijelaskan dengan baik efek merugikan bertambahnya usia pada hasil akhir cedera kepala, namun bertambahnya usia akan memberikan hasil akhir yang lebih buruk pula. Pupil bilateral fixed dan dilatasi pupil $>4 \mathrm{~mm}$ mempunyai hasil akhir yang buruk hingga $70 \% .43-45$

Berdasarkan hasil penelitian yang telah dianalisis secara statistik dari 66 data, terdapat korelasi positif yang sangat kuat antara Marshall CT Score dan mortalitas pada pasien cedera kepala sedang dan berat dengan nilai $r$ mencapai 0.943 menggunakan perhitungan spearman's rho. Hal ini sesuai dengan teori bahwa semakin tinggi nilai Marshall maka semakin tinggi angka mortalitas, tetapi akan terjadi sedikit penurunan pada kategori evacuated mass lesion (V), dikarenakan pada kategori ini dilakukan pembedahan terhadap pasien. ${ }^{1}$ Hal ini menandakan bahwa Marshall CT Score dapat digunakan sebagai prognosis pada pasien cedera kepala sedang dan berat.

Cedera otak primer, menumbuhkan rantai peristiwa yang mengarah pada kerusakan sel yang sedang berlangsung, disebut juga sebagai cedera/kerusakan otak sekunder. Cedera otak sekunder dapat diperparah oleh adanya secondary insult yang dapat menyebabkan penurunan supply oksigen ke sel-sel dan metabolisme. Secondary insult ini antara lain hipotensi, hipoksia dan peningkatan tekanan intrakranial karena adanya lesi massa. Hal inilah yang dapat menyebabkan kematian pada pasien cedera kepala. ${ }^{43}$

\section{KESIMPULAN}

1. Terdapat korelasi positif yang sangat kuat antara Marshall CT Score dan mortalitas pada penderita cedera kepala sedang dan berat di RSUD DR Abdul Aziz Kota Singkawang yang mana semakin tinggi nilai Marshall maka semakin tinggi angka mortalitas. 
2. Nilai GCS yang terbanyak pada subjek penelitian adalah 12 .

\section{Nilai Marshall CT Score terbanyak} pada sampel yaitu dalam kategori diffuse injury II, dan persentase mortalitas tertinggi pada kategori non evacuated mass lesion (VI).

4. Angka kematian pada pasien cedera kepala sedang dan berat adalah 26 orang.

\section{DAFTAR PUSTAKA}

1. Sunil M. A comparative Study Between Marshall and Rotterdam CT Scores in Predicting Early Deaths in Traumatic Brain Injury in a Major Tertiary Care Hospital in Nepal. Nepal: Elsevier; 2016.

2. De Silva MJ, Roberts I, Perel P, Edwards P, Kenward MG, Fernandes J, et al. Patient outcome after traumatic brain injury in high, middle- and low-income countries: analysis of data on 8927 patients in 46 countries. Int $\mathbf{J}$ Epidemiol; 2009.

3. Center for Disease Control and Prevention (CDC). QuickStats: Injury and traumatic brain injury-related death rates by age United States 2006. MMWR. 2010; 59: 303.

4. Mansjoer A. Kapita Selekta Kedokteran. Jakarta : Media Aesculpius; 2003.

5. Sunil M. Role of computed tomography scores and findings to predict early death in patients with traumatic brain injury: A reappraisal in a major tertiary care hospital in Nepal. Nepal: Surg Neurol Int. 2016.

6. Abelson-Mitchell N. Neurotrauma: Managing Patients with Head Injury. Oxford: John Wiley \& Sons. 2013; 200.

7. Lingsma HF, Roozenbeek B, Steyerberg EW, Murray GD dan Maas AIR. Early prognosis in traumatic brain injury: from prophecies to predictors. Lancet Neurol. 2010; 9: 543-54.

8. Badan Penelitian dan Pengembangan Kesehatan Departemen Kesehatan Republik Indonesia. Riset kesehatan dasar; 2007.

9. Riyadina W, Suhardi dan Permana M. Pola dan Determinan Sosiodemografi Cedera Akibat Kecelakaan Lalu Lintas di Indonesia. Maj Ked Indonesia. 2009; 59(10).

10. Badan Pusat Statistik Provinsi Kalimantan Barat. Kalimantan Barat dalam Angka 2015. Pontianak: BPS-Provinsi Kalimantan Barat; 2015.

11. Badan Pusat Statistik Kota Pontianak. Kota Pontianak dalam Angka 2015. Pontianak: BPS-Kota Pontianak; 2015.

12. Kepolisian Resort Kota Singkawang. Data Penyelesaian Perkara Laka Lantas Tahun 2012-2016. Singkawang: Kepolisian Negara Republik Indonesia Daerah Kalimantan Barat Resort Singkawang; 2016.

13. Burns J Jr, Hauser W. The Epidemiology of Traumatic Brain Injury : A Review. Epilepsia Suppl. 2003; 10: 2-10.

14. Sastrodiningrat AG. Memahami faktor faktor yang mempengaruhi prognosa cedera kepala berat. Majalah kedokteran nusantara. 2009; 39(3): 307-16.

15. Deepika A. Comparison of Predictability of Marshall and Rotterdam CT Scan Scoring System in Determining Early Mortality After Traumatic Brain Injury. SpringerVerlag Wien; 2015.

16. Chesnut RM. Evolving Models of Neurotrauma Critical Care; an Analysis and Call to Action. Clin Neurosurg; 2000.

17. Marshall LF, Eisenberg H. A New Classification of Head Injury Based on Computed Tomography. J Neurosurg; 1991.

18. Mass Al, Hukkelhoven, Marshall LF. Prediction of Outcome in Traumatic Brain Injury with Computed Tomographic Characteristics; a Comparison Between the Computed Tomographic Classification and Combinations of Computed Tomographic Predictors. Neurosurgery; 2005.

19. Rahul R. Prognostic Models in Traumatic Brain Injury. Finland : University of Helsinki; 2014.

20. Jacobs B, Beems T, van der Vliet TM, van Vugt AB, Hoedemaekers C, Horn J, et al. Outcome prediction in moderate and severe traumatic brain injury: a focus on computed tomography variables. Neurocrit Care. 2013; 19: 79-89.

21. Nelson DW, Nyström H, MacCallum RM, Ornquist B, Lilja A, Bellander B-M, et al. 
Extended analysis of early computed tomography scans of traumatic brain injured patients and relations to outcome. $\mathbf{J}$ Neurotrauma. 2010; 27: 51-64.

22. Zhu GW, Wang $F$ and Liu WG. Classification and Prediction of Outcome in Traumatic Brain Injury Based on Computed Tomographic Imaging. The Journal of International Medical Research. 2009; 37: 983-995.

23. Drake RL, Vogl WA dan Mitchell AWM. Gray's Basic Anatomy: Study Smart with Student Consult. Philadelphia: Elsevier. Churchill Livingstone. 2012; 433.

24. Vicki L. Methodological Issued and Research Recommendations for Prognosis After Mild Traumatic Brain Injury: Results of the International Collaboration on Mild Traumatic Brain Injury Prognosis. America: American Congress of Rehabilitation Medicine; 2014.

25. Sundstrom T, Grande PO. Management of Severe Traumatic Brain Injury: Evidence, Tricks, and Pitfalls. Heidelberg: Springer Science \& Business Media; 2012.

26. Grace PA dan Borley NR. Surgery at a Glance. Chichester: Wiley-Blackwell; 2013.

27. Peterson N dan Scardiglia J. Advanced Trauma Life Support for Doctors: ATLS Student Course Manual, edisi ke-18. Chicago: American College Surgeons. 2008; 150-153.

28. American College of Surgeons, Committee on Trauma. Advanced Trauma Life Support: Student Course Manual, edisi ke-9. Chicago: American College of Surgeons. 2012.

29. Snell RS. Clinical Neuroanatomy, edisi ke-7. Philadelphia: Wolters Kluwer. 2010; 7: 265270.

30. Gofar AS. Neurosurgery Lecture Notes FK USU. Medan : USU Press. 2012

31. American College of Surgeons Comitte. Advanced Trauma Life Support (ATLS), ninth ed. Chicago : American College of Surgeons. 2012.

32. Igbaseimokumo U. Brain CT Scans in Clinical Practice. London: Springer. 2009; 41-44.

33. Granacher RP. Traumatic Brain Injury: Methods for Clinical and Forensic Neuropsychiatric Assessment, edisi ke-3. Boca Raton: Taylor \& Francis Group. 2005; 136-140.

34. Mbemba DM. Marshall Score Better Predictor of Early Traumatic Brain Injury Death. Chicago: Neurosurgery; 2012.
35. Ono J, Yamaura A, Kubota M. Outcome Prediction in Severe Head Injury: Analyses of Clinical Prognostic Factors. J Clin Neurosc. 2001; 8: 120-123.

36. Okten AI, Gezercon Y, Ergun R. Traumatic Subaraknoid Hemorrhage: a Prospective Study of 58 Cases. Ulus Travma Acti Derg. 2006; 12: 107-114.

37. Wang F, Huang $X$, Wen L. Prognostic Value of the Marshall Computed Tomography Classification for Traumatic Brain Subaraknoid Hemorrhage. ChinaAsian Biomedicine. 2014; 8: 609-612.

38. Kumar R dan Mahapatra AK. A Textbook of Head Injury. Edisi ke-1. New Delhi: JP Medical Ltd; 2012.

39. Rowland LP dan Pedley TA. Merritt's Neurology. Edisi ke-12. Philadelphia: Lippincott Williams \& Wilkins; 2010.

40. Sherer M dan Sander AM. Handbook on the Neuropsychology of Traumatic Brain Injury. New York: Springer; 2014.

41. Takahashi $\mathrm{C}$, Hinson $\mathrm{H}$ dan Bagulay IJ. Autonomic dysfunction syndromes after acute brain injury. Edisi ke-3. Philadelphia: Elsevier; 2015.

42. Langlois J, Rutland-Brown W dan Wald M. The Epidemiology and Impact of Traumatic Brain Injury: A Brief Overview. J Head Trauma Rehabil. 2006; 21(5): 375.

43. Maas AI, Marmarou A, Murray CD, Teasdale SG, Steyerberg EW. Prognosis and clinical trial design in traumatic brain injury: the IMPACT Study. J Neurotrauma 2007; 24(2): 232-239.

44. Butcher I, Maas Ai, Lu J, Marmarou A, Murray GD, Mushkudiani NA, et al. Prognostic value of dermographic characteristic in traumatic brain injury: result from the IMPACT study, J Neurotrauma 2007; 24(2): 259-269.

45. Butcher I, Maas Ai, Lu J, Marmarou A, Murray GD, Mushkudiani NA, et al. Prognostic value of admission blood pressure in traumatic brain injury: result from the IMPACT study. J Neurotrauma 2007; 24(2): 294-302. 